\title{
Nanoemulsion Based Targeting in Cancer Therapeutics
}

\author{
Gannu Praveen Kumar ${ }^{1 *}$ and Ajmeera Divya ${ }^{2}$ \\ ${ }^{1}$ Department of Pharmaceutics, Sahasra Institute of Pharmaceutical Sciences, Near Ayyappa swamy temple, Warangal-506007, India \\ ${ }^{2}$ University College of Pharmaceutical Sciences, Kakatiya University Warangal, India
}

\begin{abstract}
The major targeting strategies that were used for the delivery of therapeutics which are explored for many of the reported nanoemulsions suggest the great potential of targeted delivery to revolutionize cancer treatment. Targeted delivery via selective cellular markers can potentially increase the efficacy and reduce the toxicity of therapeutic agents. The effectiveness of a cancer therapeutic device is measured by its ability to reduce and eliminate tumors without damaging healthy tissue. Therefore, a distinct capacity to target tumors is essential in the success of the therapeutic device. An increased site specificity and internalization can improve the efficacy of treatment and decrease the possibility of the serious side effects that cancer patients often experience. The ultimate goal of cancer therapeutics is to increase the survival time and the quality of life of the patient. Nanoemulsions offer major improvements in therapeutics through site specificity, their ability to escape from multi-drug resistance and the efficient delivery of an agent. There is large overlap between the divisions which reflect the heterogeneity of tumor biology and the large potential for multiple targeting schemes using different ligands. The objective of this review is to outline current major cancer targets for nanoemulsions and give insight into the direction of the field.
\end{abstract}

Keywords: Nanoemulsion; Cancer; Active; Passive; Ligand; Targeting

\section{Introduction}

A major hurdle in cancer diagnosis and therapy is the targeted and efficacious delivery of agents to the tumor site, while avoiding adverse damage resulting from systemic administration. While systemic drug delivery already hinges largely on physicochemical properties of the drug, such as size, diffusivity, and plasma protein binding affinity, tumors possess a dense, heterogeneous vasculature and an outward net convective flow that act as hurdles to efficient drug deposition at the target site. Nanocarrier mediated delivery has emerged as a successful strategy to enhance delivery of therapeutics and imaging agents to tumors, thereby increasing the potential for diagnosis at an earlier stage or for therapeutic success (or both).

Nanosystems like nanoparticles, liposomes, micelles, nanoemulsions, dendrimers and nanocapsules are explored to deliver to the target site. Stability of nanosystems is difficult because of their large surface area. Additionally, the charactheristics of nanosystems must be fully understood to achieve optimum in vivo efficiacy. On the other hand, some of these nanomaterials toxicology has not been fully revealed, preclinical and clinical studies are required to reveal and understand toxicity of these materials. Long-term toxicity and stability must be studied before using them in human health care. Behaviours of nanosystems should be investigated in the human body. They may trigger blood coagulation pathways and may cross the physiological barriers such as blood-brain barrier unintentionally. Also, the toxicity parameters of bulk material can be changed by using them in a nanoformulation. Therefore, toxicity parameters must be examined before they generate formulation for all ingredients which are used in nanoscale. Since oils and surfactants are used in nanoemulsion whose safety is already established, these systems can be used more successfully. Nanoemulsions are heterogeneous dispersions of two immiscible liquids (oil-in-water or water-in-oil) having a mean droplet size in the nanometric scale as shown in Figure 1, regardless of method of preparation. The major advantages of nanoemulsions include site specific delivery of drugs, capacity to dissolve large quantities of hydrophobics, ability to protect drugs from degradation with long term stability thus making an ideal drug delivery system. The frequency and dosage of injections can be reduced throughout the therapy as the release pattern of drugs takes place in a sustained and controlled mode over long periods of time [1]. It is reported that an injectable vitamin $\mathrm{E}$ based paclitaxel nanoemulsion is found to be better tolerated and more efficacious than taxol in the melanoma tumor model mice. There is an enormous interest to develop active targeted long circulating parenteral nanoemulsions when designed to reach nonRES tissues in the vascular system [2]. It is proved that nanoemulsion may bypass RES mainly the kupffer cells of the liver by modulating the rate of intravenous administration [3]. The concept of saturation of RES to bypass the clearance is supported by either single large doses or repeated administration [4]. Therefore, to improve the circulation time of nanodroplets, either of the two different approaches can be applied.

One is the use of structured lipids as oil core and the second involve surface modification using a coemulsifier with highly hydrophilic chains like polyoxyethylene (POE) and amphipathic polyethylene glycol (PEG) derivatives. Nanoemulsion using structured lipids are prepared and explored for its potential to prolong the in vivo circulation time [5]. In another study, nanoemulsion for lipophilic drugs is developed for prolonged circulation in the blood in which a coating with sphingomyelin (SM) in the surface of the oil droplets results in avoidance of the RES [6]. Similarly, it is demonstrated further that nanoemulsion containing SM survive in the circulation for a considerably longer period and ultimately delays the removal from rat plasma $[7,8]$. Since long circulation is an important prerequisite for cancer treatment, it is reported that sterically stabilized nanoemulsions containing HCO60 as an emulsifier prove as effective carriers for highly lipophilic antitumor agents to enhance the drug delivery to tumors since long circulation times enable effective transport to the tumor site through the EPR effect with the resultant endocytosis of the nanoemulsion [9]. Also, the effect of HCOs on the pharmacokinetics of menatetrenone in soybean oil (SO) based nanoemulsion in rats demonstrate the prolongation of the plasma circulation time. These studies suggest the involvement of oil

*Corresponding author: Gannu Praveen Kumar, Department of Pharmaceutics, Sahasra Institute of Pharmaceutical Sciences, Near Ayyappa swamy temple, Warangal-506007, India, Tel: +91-9397398024; E-mail: ghalo2010@gmail.com

Received February 08, 2015; Accepted June 22, 2015; Published June 24, 2015

Citation: Praveen Kumar G, Divya A (2015) Nanoemulsion Based Targeting in Cancer Therapeutics. Med chem 5: 272-284. doi: 10.4172/2161-0444.1000275

Copyright: ๑ 2015 Kumar GP, et al. This is an open-access article distributed under the terms of the Creative Commons Attribution License, which permits unrestricted use, distribution, and reproduction in any medium, provided the original author and source are credited. 
or structured lipids in the enhancement of systemic circulation of the nanoemulsion [10]. Stearic barrier or enhanced hydrophilicity effect exerted by POE chain when added as coemulsifier to the phospholipidstabilized NE allow passive or active targeting [11,12]. Addition of POE-based surfactants into the otherwise hydrophobic phospholipidstabilized nanoemulsion is particularly effective against plasma protein adsorption onto nanoemulsion surfaces because of the hydrophilicity and unique solution properties of POE-based surfactants, including minimal interfacial free energy with water, high aqueous solubility, high mobility and large exclusion volume [13]. The modification of nanoemulsion using amphipathic PEG-containing molecules results in the prolongation of their blood circulation time [14,15]. Similarly, it is reported that addition of PEG-PE to dipalmitoyl phosphatidylcholine nanoemulsion prolongs clearance rate especially during first $3 \mathrm{~h}$. A further addition of cosurfactant polysorbate 80 or pluronics F-68 results in a marked extension of the circulation lifetime during first $6 \mathrm{~h}$. The notable effects of polysorbate 80 and pluronic F- 68 can apparently be attributed mainly to the decrease in droplet size and hydrophilicity [16]. Therefore, it is evident from the studies that nanoemulsions can be passively or actively targeted especially to the tumor site by prolonging the circulation time. There are numerous nanoemulsion formulations which are patented (Table 1) and anticancer drugs incorporated in nanosystems which are commercially available in the market of which some are listed in Table 2. Thus, the number of patents growing year by year and increasing marketed nanoemulsion formulations explains the scope for commercial viability (Figure 2).

Absence of toxicity either in vivo or in the environment (as a byproduct) is one of the most important features that nanocarriers intended for drug delivery applications should possess. In this sense, lipid-based nanosystems are probably the least toxic for clinical applications. The hydrophobic constituents of lipid-based systems provide a suitable environment for entrapment of hydrophobic drugs, which represent about $40 \%$ of newly developed drugs. Lipid based drug delivery systems have been particularly recognized as innovative formulation approaches capable of enhancing lipophilic drug absorption and thus clinical efficacy. Since nanoemulsions are excellent vehicles for solubilization and transport of hydrophobic and/or hydrophilic active compounds with unique physical properties. Hence extensive research has been conducted on the formation, characterization, and potential applications of nanoemulsions in cancer therapy. They are among the first of colloidal systems for cancer that have been either examined, or exploited, as vehicles for the delivery of therapeutic agents. The present review focuses on a comprehensive discussion of the use of nanoemulsions in anti-cancer therapy, reporting the technological aspects of pharmaceutical formulation of these carriers, and exploiting their advantages in targeting to cancers (Figure 3).

\section{Need for Nanoemulsion Based Targeted Drug Delivery Systems for Cancer}

According to estimates from the International Agency for Research on Cancer (IARC), by 2030, cancer is expected to grow up to 21.4 million new cancer cases and 13.2 million cancer deaths [17]. This change dramatically increases the total number of cancers diagnosed each year, with a 67 percent increase in cancer incidence anticipated for the segment of the population aged 65 or over [1820]. So, among the different available nanocarriers such as different nanoparticles, liposomes, niosomes, micelles, lipoproteins and different nanoassemblies [21], that have the potential to deliver to tumor tissue,
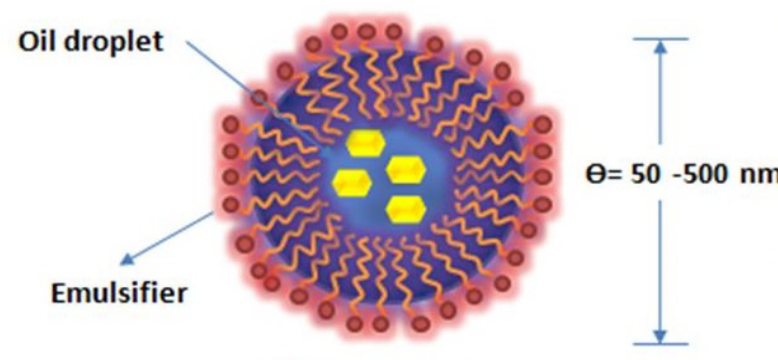

\section{Hydrophobic Drug}

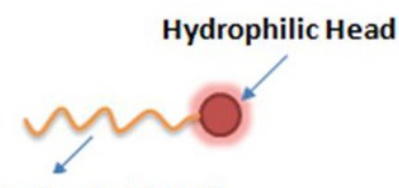

Hydrophobic Tail

Emulsifier Molecule

\section{o/w Nanoemulsion}

Figure 1: Nanoemulsion droplet.

\begin{tabular}{|c|c|c|}
\hline Nanoemulsion & Company & Patent number \\
\hline $\begin{array}{l}\text { Fluid non-ionic amphiphilic lipids and use in cosmetics or in } \\
\text { dermopharmaceuticals }\end{array}$ & L'Oreal (Paris,FR) & US Patent number: $5,753,241$ \\
\hline $\begin{array}{c}\text { Sugar fatty ethers and its uses in the cosmetics, dermatological and/ } \\
\text { ophthalmological fields }\end{array}$ & L'Oreal (Paris,FR) & US Patent number: $6,689,371$ \\
\hline Non-toxic antimicrobial compositions and methods of use & NanoBio Corporation US & US Patent Number: $6,559,189$ \\
\hline Method of preventing and treating microbial infections & NanoBio Corporation US & Patent Number: $6,506,803$ \\
\hline 5-aminolevulinic acid & ASATAG Applied Science and Technology $(\mathrm{Zug}, \mathrm{CH})$ & PCT/EP99/08711 \\
\hline
\end{tabular}

Table 1: Patents on nanoemulsion formulations.

\begin{tabular}{|c|c|c|c|}
\hline Drug/Bioactive & Brand name & Manufacturer \\
\hline Palmitate alprostadil & Liple & Mitsubishi pharmaceutical, Japan & Vasodilator, platelet inhibitor \\
\hline Dexamethasone & Limethason & Mitsubishi pharmaceutical, Japan & Steroid \\
\hline Propofol & Diprivan & Kaken pharmaceutical, Japan & Anaesthetic \\
\hline Flurbiprofenaxtil & Ropion & NSAID & Fresenius Kabi, Europe \\
\hline Vitamins A,D,E and K & Vitalipid & Parenteral nutrition \\
\hline
\end{tabular}

Table 2: Commercial nanoemulsion formulations. 


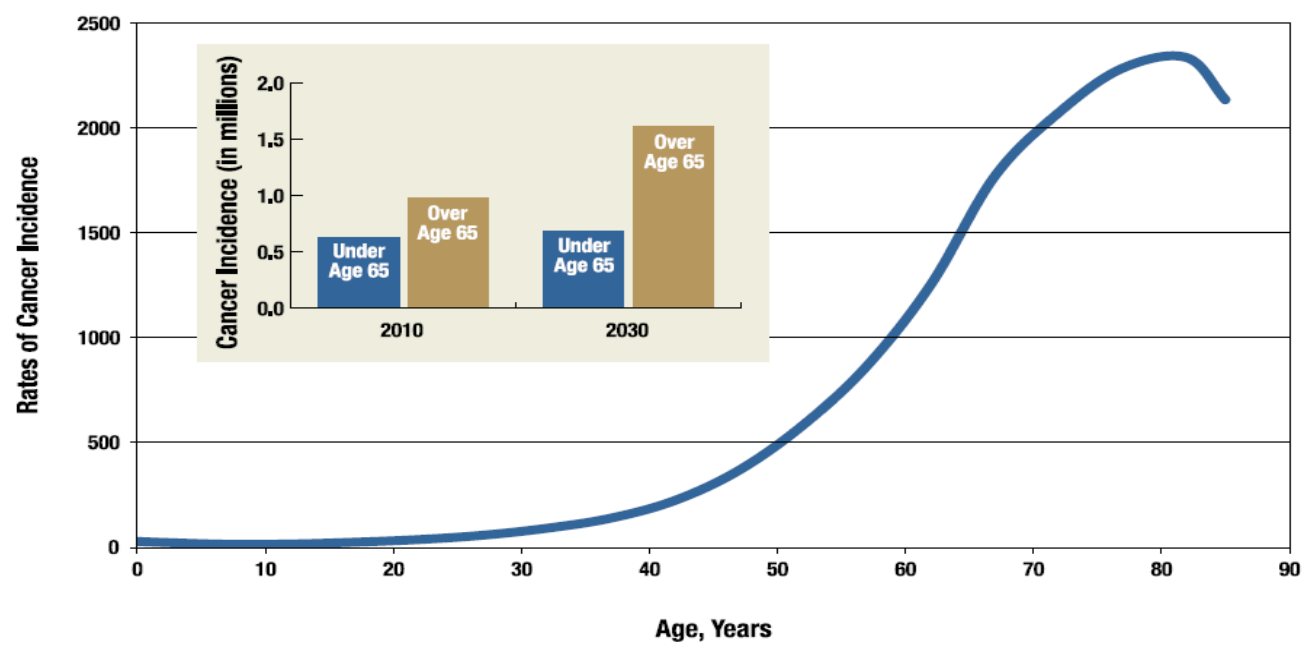

Figure 2: Drive up cancer incidence.

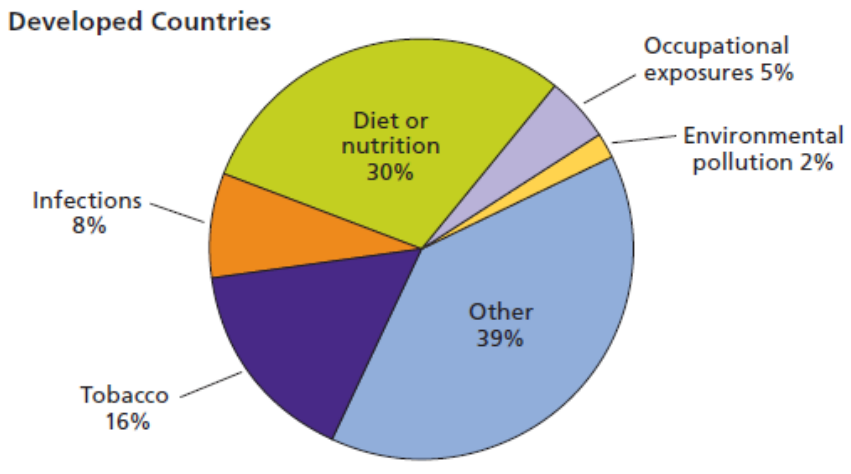

Developing Countries

Figure 3: Causes of cancer.

oil-in-water $(\mathrm{o} / \mathrm{w})$ type nanosized emulsion $(\mathrm{NE})$ is ideal to resolve these challenges owing to its self assembled nature that is intrinsically responsive to its immediate environment and the versatility of the components which can be combined to result in structures with multiple responsive functionalities. The effectiveness of passive tumor specific drug delivery can be achieved on the basis of the morphological and physiological differences between cancer and normal cells. For example, the leaky vasculature of cancer cells (EPR effect) allows molecules and nanoemulsions to easily enter the extravascular spaces while the undeveloped lymphatic drainage in cancer cells does not allow them to leave the tumor. Another approach for effective tumor specific drug delivery is to actively target over expressed receptors as molecular targets. Since rapidly growing tumor needs various nutrients and vitamins in large quantities compared to normal cells, tumor cells over express many tumor-specific receptors, which can be used as targets to deliver cytotoxic agents into tumors. Most of them are currently used in the clinic as biomarkers for tumor diagnosis. EGFR, PRSS8, FOLR1, ALDH1, O-B2, VPAC1, IGF-1R, mRNAs include some of the examples for biomarkers used in detection of various cancer types. By exploiting the difference between the rate of expression of these biomarkers in normal and tumor tissues, conjugation of substances that can selectively bind to the over expressed receptors using suitable linkers that demonstrate selective drug delivery to the tumor site through receptor mediated endocytosis. The conventional chemotherapy uses cytotoxic agents that are expected to act on rapidly proliferating cancer cells and eventually kill them, but because of nonspecificity leads to systemic toxicity and undesirable severe side effects. Hence, researchers made efforts to develop tumor targeting drug delivery systems, the concept originated from Magic bullet idea for targeting [22], which can selectively transport cytotoxic agents to the tumor site thereby limiting harm to the healthy tissues. In recent years, considerable effort has been directed towards developing nanoemulsions as vaccine carriers in tumors. Some of these have recently been described for the mucosal route vaccination against infectious diseases, such as hepatitis B [23], HIV [24], and influenza [25]. Nanoemulsions offer the versatility of delivering macromolecules, like antigenic proteins and peptides, either locally or systemically, resulting in potent humoral and cellular antigenspecific immune responses to tumor. A special type of immune cell called a T cell was the pivotal sentinel in the immune system's response against cancer. This elaboration led to the coinage of the term "immune surveillance or immunosurveillance" to describe the concept whereby the immune system is on perpetual alert against transformed cells. The theory of immunosurveillance remained controversial with the concept IFN-gamma and lymphocytes prevent primary tumor development and shape tumor immunogenicity. Utilizing genetically engineered mice that lacked a functional immune system, the authors showed that lymphocytes and the immune stimulator, IFN-gamma, cooperate to inhibit the development of both spontaneous and carcinogen-induced tumors. So, even tumors that have escaped recognition can be turned into targets for an immune response. In terms of vaccine delivery, 
nanoemulsions possess several advantages, including long circulatory times and increased cellular uptake by APCs. The PEGylated LBT-OAnanoemulsion shows significantly higher concentration of LBT in the lung tumor tissue when compared to free LBT and also exhibits higher growth inhibitory effect and longer survival time than free LBT in both heterotopic and lung metastatic tumor models. In another study, nanoemulsions produced and characterized using hyperpolarized ${ }^{129} \mathrm{Xe}$ combined with CEST detection are detected at concentrations as low as $100 \mathrm{fM}$, corresponding to $<1 \mu \mathrm{L}$ of perfluorocarbon per liter of solution. The straightforward, inexpensive production of these agents will facilitate future development toward molecular imaging and chemical sensing applications in tumor diagnosis. Recently, a vaccine that aims to co-deliver immunostimulatory $\mathrm{CpG}$ and gastriccancer-specific antigen, MG7 is developed [26-28]. It is observed that mice immunized with MG7 and CpG co-encapsulated in these nanoemulsions prepared with soya bean oil using magnetic ultra sound method show significant inhibition of tumor growth after challenge with MG7-expressing carcinoma cells. On similar lines, melanomatargeted nanoemulsion vaccines are prepared by encapsulating heat shock protein 70 and staphylococcal enterotoxins A [29-32] which are proposed to augment induction of tumor-specific immunity. In mice studies, this group also demonstrated that delivery of MAGE1/HSP70/SEA encapsulated within a nanoemulsion significantly enhanced tumor-specific responses and protection, as compared to non-encapsulated delivery. Tumor cells express antigens that can be recognized by the host's immune system. These tumor specific antigens (TSA) can generate tumor specific cytotoxic T lymphocyte (CTL) and damage tumor cell. Today, tumor vaccine has played an important role in prevention and therapy of tumor and has been regarded as the most attractive method. The melanoma antigen (MAGE-1) was the first reported tumor specific antigen, which can induce specific CTL and show potency in tumor immunotherapy. As molecular chaperone, HSP participates in processing and presentation of tumor antigen and play an important role in eliciting antitumor immunity. MAGE-1 and HSP70 fusion protein can efficiently elicit MAGE-1-specific antitumor immunity and enhance the potency of MAGE-1 protein vaccine. However, protein vaccine still has some serious limitations. First, the activation of antigen-specific CTL responses requires the delivery of signals from $\mathrm{CD}^{+}$cells, monocytes and granulocytes recruited at the site of vaccination. Such signals may not be provided by antigen protein alone. Second, proteins are unstable, high molecular weight, hydrophilic, complicated in structure, larger in size, they are harder to deliver by conventional ways as compared to classical molecules. The main barriers to successful delivery of protein are enzymatic barriers and absorption barriers imposed by gastrointestinal tract. So it is important to change the formulation of proteins to maximize physical and chemical stability, prolong biological half-life, increase absorption and minimize metabolism. MAGE-1-HSP70 fusion protein and Staphylococcal enterotoxin (superantigen SEA) are mixed in a suitable ratio as complex protein vaccine. Then, this vaccine is captured in nanoemulsion which is a kind of protein in drug carrier and the efficieny of this system can be tested in two different ways.

A. The first efficiency is generally investigated by evaluating their humoral and cellular antitumor immunity and therapeutic effects against established tumor expressing MAGE-1. The nanoemulsion is cocultured with Murine tumor cells (humoral response) in-vitro and macrophages in-vivo (cellular response). The uptake of Nanoemsulsion by DCs and M are detected by confocal microscopy.

B. The second efficiency is generally investigated by evaluating the therapeutic effects against established tumor expressing MAGE-
1. The therapeutic effect is evaluated as follows. The mice with B16-MAGE1 melanoma is immunized using nanoemulsion containing MAGE-1-HSP70/SEA and then the spleen lymphocytes are isolated. The presence of MAGE-1 specific T lymphocytes are then identified by ELISPOT assay. The antitumor immunity is detected by Enzyme-linked immunospot assay (ELISPOT) and cytotoxicity assays. ELISPOT and Cytotoxicity assays show the immunization using NE complex vaccine enchanced the frequency of splenocytes secreting Y-IFN significantly. Cytotoxicity assays show the MAGE1 B16 Lysis of CTLs from mice immunized with NE complex vaccine. The tumor masses formed in the mice immunized with NE complex vaccines will be markedly smaller than those immunized with free complex vaccines. The mice planted tumor of B16-MAGE-1 will have significantly longer survival times, after therapy with NE complex vaccine.

Currently, pre-clinical and phase I trials with nanoemulsion vaccine formulations have only targeted hepatitis B [23] and seasonal influenza. Promising tumor protection data from animal studies demonstrate safety and stability of nanoemulsion formulations which provide a platform to perform clinical trials in cancer patients. From these studies, it is clear that nanoemulsions can incorporate small molecules to macromolecules to deliver to the tumor site and few examples are shown in Table 3.

\section{The Challenges of Multidrug Resistance}

The molecular basis of cancer drug resistance is complex and correlated to elevated levels of enzymes that can neutralize chemotherapeutic drugs. More often, it is due to the over expression of MDR transporters that actively pump chemotherapeutic drugs out of the cell and reduce the intracellular drug doses below lethal threshold levels. Because not all cancer cells express the MDR transporters, chemotherapy will kill only drug-sensitive cells that do not or only mildly express MDR transporters, while leaving behind a small population of drug resistant cells that highly express MDR transporters. With tumour recurrence, chemotherapy may fail because residual drug-resistant cells dominate the tumour population [33]. There are various MDR transporters among which the most widely investigated proteins are P-glycoprotein (MDR1 or ABCB1), the multidrug resistance associated proteins (MRPs), of which the most studied is the MRP1 or ABCC and the breast cancer resistance protein (ABCG2) [34]. These proteins have different structures, but they share a similar function of expelling chemotherapy drugs from the cells. Several studies have demonstrated the possibility of using nanocarriers to bypass the MDR transporters. Combination treatments with targeted nanocarriers for selective delivery of drugs and MDR pump inhibitors will likely address some of the problems posed by resistant tumours. Heterogeneity and mutations among cancer cells help develop certain mechanisms, responsible for eluding chemotherapy,

\begin{tabular}{|c|c|c|}
\hline Drug & Formulation & Outcome \\
\hline $\begin{array}{c}\text { Benzyl } \\
\text { isothiocyanate }\end{array}$ & $\begin{array}{c}\text { Flax seeds oil based } \\
\text { nanoemulsion }\end{array}$ & $\begin{array}{c}\text { In-vitro cytotoxicity against } \\
\text { A549 and SKOV-3 cell lines. }\end{array}$ \\
\hline Curcumin & $\begin{array}{c}\text { Lecithin based } \\
\text { microemulsion }\end{array}$ & $\begin{array}{c}\text { In-vitro cytotoxicity against OSCC- } \\
4 \text { and OSCC-25 cell lines. }\end{array}$ \\
\hline Melphalan & $\begin{array}{c}\text { Capmul MCM based } \\
\text { nanoemulsion }\end{array}$ & $\begin{array}{c}\text { 2-fold higher } \\
\text { distribution in ovaries. }\end{array}$ \\
\hline Methotrexate & $\begin{array}{c}\text { Soyabean oil based } \\
\text { microemulsion }\end{array}$ & $\begin{array}{c}\text { In-vitro cytotoxicity against MCF-7 } \\
\text { cell lines. }\end{array}$ \\
\hline Paclitaxel & $\begin{array}{c}\text { Drug loaded nanoemulsion } \\
\text { co-administered with } \\
\text { curcumin }\end{array}$ & $\begin{array}{c}\text { 3.2-fold increase in } \\
\text { tumor uptake. }\end{array}$ \\
\hline
\end{tabular}

Table 3: Anticancer agents benefited by nanoemulsions. 
which improve their survival odds. The cellular factors responsible for subtherapeutic drug concentration in the tumor cell (Figure 4) are attributed to decreased drug influx, increased drug efflux, increased drug metabolism, increased DNA repair, lack of apoptotic machinery and increased antiapoptotic machineries. From Table 4 it is evident that many of the anticancer drugs are potential substrates for transporters which require nanocarriers like nanoemulsions to overcome resistance and deliver the drug to the target site.

Development of multidrug resistance (MDR) against a variety of conventional and novel chemotherapeutic agents is a significant challenge in effective cancer therapy. Over several years, focus is made on a multimodal therapeutic strategy to overcome tumor MDR by enhancing the delivery efficiency to the tumor mass and lowering the apoptotic threshold by modulation of the intracellular signaling mechanisms. Combination PTX and CUR therapy, when administered in the nanoemulsion formulations, is very effective in enhancing the cytotoxicity in wild-type SKOV3 and drug resistant SKOV3TR human ovarian adenocarcinoma cells by promoting the apoptotic response which is useful in the clinical management of refractory diseases, especially in ovarian cancer [35].

\section{Efficiency of the Drug Delivery System (Nanoemulsion)}

Among the nano drug delivery carriers being aggressively explored for treatment of brain cancer, nanoemulsions are among the more recent ones. Specific features of these systems present them as attractive drug delivery systems with good potential for delivery to the brain.

The small size of the oil droplets generally $<100 \mathrm{~nm}$, imparts inherent stealth features. The design of functional and multifunctional nanoemulsion could, through synergistic effects of different components, enable enhanced transport of drug across the BBB. Many anti-cancer drugs are highly hydrophobic and these are readily incorporated in nanoemulsions. They are versatile nanocarriers and can permit loading of both hydrophobic and hydrophilic drugs. A combination of anti-cancer drugs may also be readily incorporated. Furthermore, they can be tailored to incorporate functional and multifunctional features to maximise brain uptake. Nanoemulsions may also be suitable alternatives in cancer chemotherapy as vehicles for prolonging the drug release after intramuscular and intratumoural injection (w/o systems) and as a means of enhancing the transport of chemotherapeutics via the lymphatic system. Positively charged nanoemulsion systems are expected to interact with negatively charged cell surfaces more efficiently, and this aspect of the positively charged nanoemulsions has been explored for the possibility of oligonucleotide delivery to cancer cells.

\section{Tumor Targeting Moieties}

Tumor targeting conjugates bearing cytotoxic agents can be classified into several groups based on the type of cancer recognition moieties. The targeting moieties are important to the mechanism of cellular uptake.

\section{Monoclonal Antibodies}

The use of monoclonal antibodies (MAbs) with specific affinity towards tumor associated antigens is an efficient immunological approach in clinical diagnosis and cancer therapy [36,37]. Although the pharmaceutical industry focuses its efforts to improve the treatment efficiency in oncology with humanized or fully human MAbs, clinical success is not guaranteed. It is now clear that the therapeutic activity of many, if not most of the anticancer MAbs is considerably enhanced following combination with chemotherapy [38,39]. One approach to improve MAbs therapeutic activity is to conjugate MAbs to chemotherapeutic drugs $[40,41]$. However, the main weakness of these drug-MAb conjugates is their insufficient therapeutic effect due to the coupling of one or a few molecules of drug per antibody molecule. Currently there is only one drug-MAb conjugated approved product (Mylotarg ${ }^{\oplus}$, Wyeth Philadelphia, PA), a humanized IgG4 anti CD-33 MAb linked to calicheamicin for the treatment of acute myeloid leukemia. MAb and MAb-conjugate treatments are considered to be highly significant but they have not yet reached their full potential. Another promising strategy for improving cancer therapy is the conjugation of MAbs to drug loaded nanoemulsions wherein MAbs are the targeting moieties. High payloads of cytotoxic drugs can be delivered to the site of action by coupling at least 20 antibody molecules on the surface of each droplet, resulting in an increase binding affinity for the targeted antigens. It is also possible to conjugate more than one antibody to droplet for the purpose of enhancing the immunological

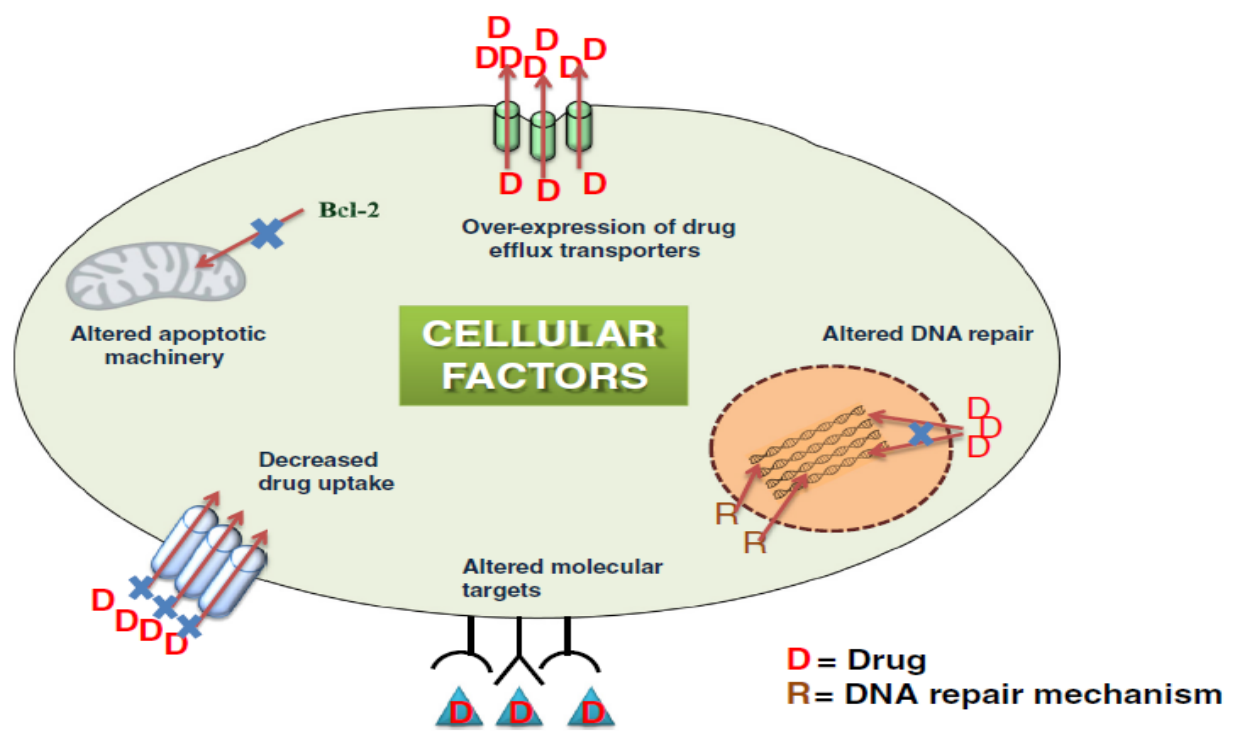

Figure 4: Cellular factors responsible for the multidrug resistance. 


\begin{tabular}{|c|c|}
\hline Transporters & Substrates \\
\hline ABCB1(MDR1, P-gp) & Doxorubicin, daunorubicin \\
\hline ABCB4 & Paclitaxel, vinblastine \\
\hline ABCC1 (MRP1) & Doxorubicin, etoposide, vincristine \\
\hline ABCC2 & Doxorubin, cisplatin, vincristine \\
\hline ABCC3 & Etoposide, methotrexate, doxorubicin \\
\hline ABCG2 & Doxorubicin, daunorubicin, mitoxantrone \\
\hline
\end{tabular}

Table 4: Transporters and substrates (anticancer agents).

and therapeutic activity as reflected by the coupling of a targeting MAb and a therapeutic MAb to the same carrier. Over the past few years different immunoemulsions [42-44] have been extensively investigated. In a study, cationic nanoemulsion-AMB8LK conjugate using maleimide as a linker is developed to target tumors over-expressing $\mathrm{H}$-ferritin. The coupling of AMB8LK Fab fragment to cationic emulsion increase the cell uptake by $50 \%$ as compared to non-conjugated cationic emulsion. The structure of the droplet with the fragment is shown in Figure 5 [45].

Similarly, long-circulating submicron lipid emulsions, stabilized with poly (ethylene glycol)-modified phosphatidylethanolamine (PEG-PE), are conjugated with anti-B-cell lymphoma monoclonal antibody LL2 by the use of a novel poly (ethylene glycol)-based hetero bifunctional coupling agent. Direct cellular ELISA reveals binding of emulsion-LL2 complexes to three types of Burkitt's lymphoma cell lines, Raji, Ramos and Daudi which prove to be a useful specific delivery of anticancer drugs to B-cell malignancy [43]. Monoclonal antibody 34A, which specifically binds to a surface glycoprotein (thrombomodulin) of the pulmonary endothelial cell surface in mice, is conjugated to the surface of castor oil nanoemulsion coupled to distearoylphosphatidylethanolamine. Kinetic studies show that emulsion targeting to the lung is very rapid. Five minutes after tail vein injection, the total amount of emulsion found in the lung is highest among the time points examined, indicating the completion of lung binding [46]. In a recent finding, an anti-CD74 antibody (Ab), LL1, is covalently attached to the surface of sterically stabilized nanoemulsion by PEG-based heterobifunctional coupling agent. In vitro 3-(4,5-dimethylthiazol-2-yl)-2,5-diphenyltetrazolium bromide (MTT) cytotoxicity tests against neoplastic B-cells has IC30 values of 0.45, for the prodrug FUdR-dO in LL1-emulsions. In the light of the extensive and specific delivery of LL1-lipid drug-carriers to B-cells and the selective cytotoxicity of the incorporated drug, nanoemulsions are found to be more effective on the elimination of circulating malignant B-cells in vivo [47]. From these studies it is very much evident about the usage of monoclonal antibodies to target tumor.

\section{Peptides as Tumor Targeting Moieties}

Peptide based targeting is an attractive approach in tumor specific drug delivery because high affinity sequences can be discovered through screening of combinatorial libraries. During the past decade, peptide receptors are successfully used for in-vivo targeting in human cancers. Peptides and their truncated analogs, possessing appropriate recognition properties, serve as tumor targeting molecules in combination with cytotoxic agents. The use of nonradiolabeled, noncytotoxic peptide analogs for long-term antiproliferative treatment of tumors appears promising for only a few tumor types, whereas the symptomatic treatment of neuroendocrine tumors by somatostatin analogs is clearly successful [44]. Since their action is mediated through specific membrane bound receptors and their interaction for TCRInduced T Cell activation for tumors is exhaustively studied [48]. Longterm treatment with adequate peptide analogs may be able to reduce or stop tumor growth. A study demonstrates significant tumor growth inhibition or even to stop the growth by use of specific, nonradioactive and noncytotoxic peptide analogs $[49,50]$. The low density lipoprotein (LDL) receptor which is upregulated in GBM (glioblastoma multiforme) tumor cells can be a potential molecular target for the delivery of therapeutic agents. Efficient cell killing is observed with nano-LDL which contains paclitaxel oleate constructed by combining a synthetic peptide and the LDL receptor (LDLR) binding domain of apolipoprotein B-100 with a lipid emulsion [51]. In another study, after single-dose subcutaneous injection in mice, it is found that the RAH peptide formulated with $\mathrm{RAH} / \mathrm{PELC} / \mathrm{CpG}$ nanoemulsion as shown in Figure 6, results in increased numbers of IFN- $\gamma$-secreting cells and $\mathrm{RAH}$-specific $\mathrm{CD} 8^{+} \mathrm{T}$ cells and an enhanced cytotoxic $\mathrm{T}$ cell response and induces complete tumor regression. These results demonstrate that peptide antigen formulated with nanoemulsions is effective for cancer immunotherapy [52].

\section{Folate as Tumor Targeting Ligand}

Folic acid has a very long history in cancer chemotherapy. It appears very popular in prodrug design because it is a small molecule and readily available, besides the fact that the distribution of the folic acid (Figure 7) receptors in tumors is well described. Folic acid is ideally suited for the design of tumor-targeting macromolecules and nanoemulsions [52]. Folic acid, a low molecular weight vitamin compound, shows a great deal of promise as a tumor-targeting agent. Folic acid shows high affinity for folate receptor (FR), one of the well recognized tumor biomarkers. It is a glycosylphosphatidylinositollinked protein that captures its ligands and transports them into the cell through a non-destructive endosomal pathway [53]. Folate receptors are highly expressed in epithelial, ovarian, cervical, breast, lung, kidney, colorectal, and brain tumors. Sarcomas, lymphomas, and cancers of the pancreas, testicles, bladder, prostate, and liver often do not show elevated levels of folate receptors. When expressed in normal tissue, folate receptors are restricted to the lungs, kidneys, placenta, and choroid plexus. In these tissues, the receptors are limited to the apical surface of polarized epithelia. The folate receptor appears to be a promising target for cancer imaging and treatment. Folate receptors are highly overexpressed on the surface of many tumor types. This expression can be exploited to target therapeutic compounds directly to cancerous tissues using many avenues. The successful use of folate conjugates indicates that receptor targeted nanoparticle treatments are a likely candidate for managing cancer. FR expression is up-regulated in more than $90 \%$ of ovarian carcinomas. This is also found at high to moderate levels in kidney, brain, lung, and breast carcinomas while at very low levels in most of the normal tissues [54]. Folate ligands are widely used for targeting because they are inexpensive, nontoxic, nonimmunogenic, easy to conjugate to carriers, retain high binding affinity and are stable in storage and in circulation [55]. The Folate receptor density also appears to increase as the stage of the cancer worsens [56]. A wide variety of molecules and drug carriers, including imaging agents, chemotherapeutic agents, oligonucleotides, proteins, haptens, liposomes, nanoparticles and gene transfer vectors have been conjugated to folate and evaluated for FR-targeted delivery. Substantial targeting efficacy has been found both in vitro and in vivo. FR- $\alpha$ is a useful marker for cancer while FR- $\beta$ is a marker for myeloid leukemia and chronic inflammatory diseases. FR-targeted agents have shown promising efficacy in preclinical models and significant potential for future clinical application in a wide range of diseases [57]. It is reported that folate $\mathrm{PFC} /$ rhodamine nanoemulsion has a great potential to serve as a useful targeting of FR positive tumor. The phospholipidanchored folate nanoemulsion is developed to improve the ability to target folate receptor expressing tumors. These nanoprobes successfully delivere to FR-positive tumor xenograft models and show significantly enhanced signal intensities of 19F-MRI and fluorescence imaging in 


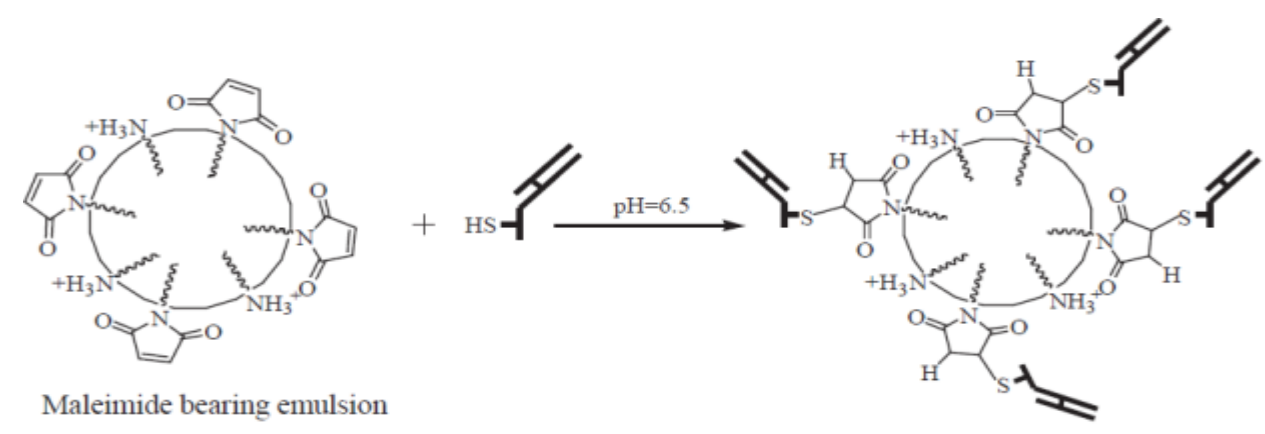

Fab' Immunoemulsion

Figure 5: Immunoemulsion.

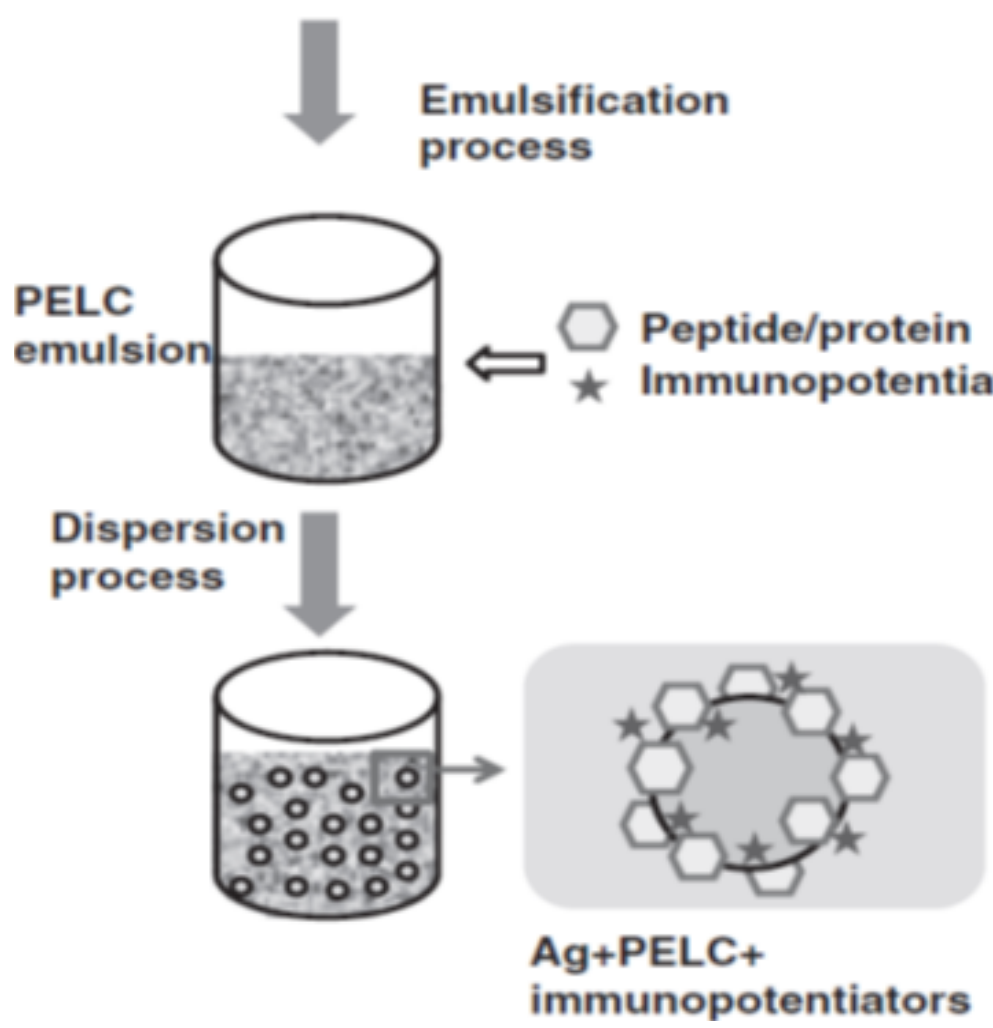

Figure 6: PELC-formulated peptide/protein vaccine.

the tumor area [58]. FR- $\alpha$, FR- $\beta$ and FR- $\gamma$ are the subtypes of folate receptors. Among these three subtypes, FR- $\alpha$ and FR- $\beta$ are membrane bound GPI-anchored proteins while the FR- $\gamma$ lacks an efficient signal for GPI modification [59]. All FR isoforms can bind folic acid but with varying affinities. FR- $\alpha$ binds the physiologic (6S) diastereoisomer of 5-mTHF and 5-formyl THF greater than folic acid but FR- $\beta$ binds these folates more than 50 -fold low affinity. In contrast, FR $\beta$ binds (6R) forms up to 12 times more tightly than (6S) forms [60]. Also tissue specificity dictates functional differences within these isoforms. FOLR2 is predominantly expressed in normal hematopoietic and in placental cells, yet only FOLR2 expressed in placenta binds folate [61].

\section{Folate Targeting to Breast Cancer}

It is estimated that 2.9 million live with a history of invasive breast cancer. Efforts are made in areas like Targeting to folate receptors for improved therapy for breast cancer. A study undertook an immunohistochemical evaluation of $\alpha$-FR expression in breast cancer samples, using a newly described monoclonal antibody, 26B3 and report that in metastatic breast cancer, $\alpha$-FR shows to be expressed in $86 \%$ of patients bearing Tumor necrotic breast cancer [62]. In a study, Fish oil based nanoemulsions rich in omega-3 PUFA show rapid uptake of the DOX stearate and the cellular uptake of the breast and distribution studies reveal that nanoemulsions are internalized by the cells. The cytotoxicity results demonstrate that nanoemulsions have lower IC50 value as compared to free drug in solution [63]. A report states that intralesional injection of a lipid nanoemulsion shows higher drug targeting in neoadjuvant chemotherapy in breast cancer treatment. It shows greatest uptake by the tumor as well as the greatest concentration in tumor compared to normal tissue [59]. It can be understood that nanoemulsions can be very well targeted to the breast tumor which is rich in folate receptors (Figure 8). 
<smiles>Nc1nc(O)c2nc(CNc3ccc(C(=O)N[C@@H](CCC(=O)O)C(=O)O)cc3)cnc2n1</smiles>

Figure 7: Structure of folic acid.

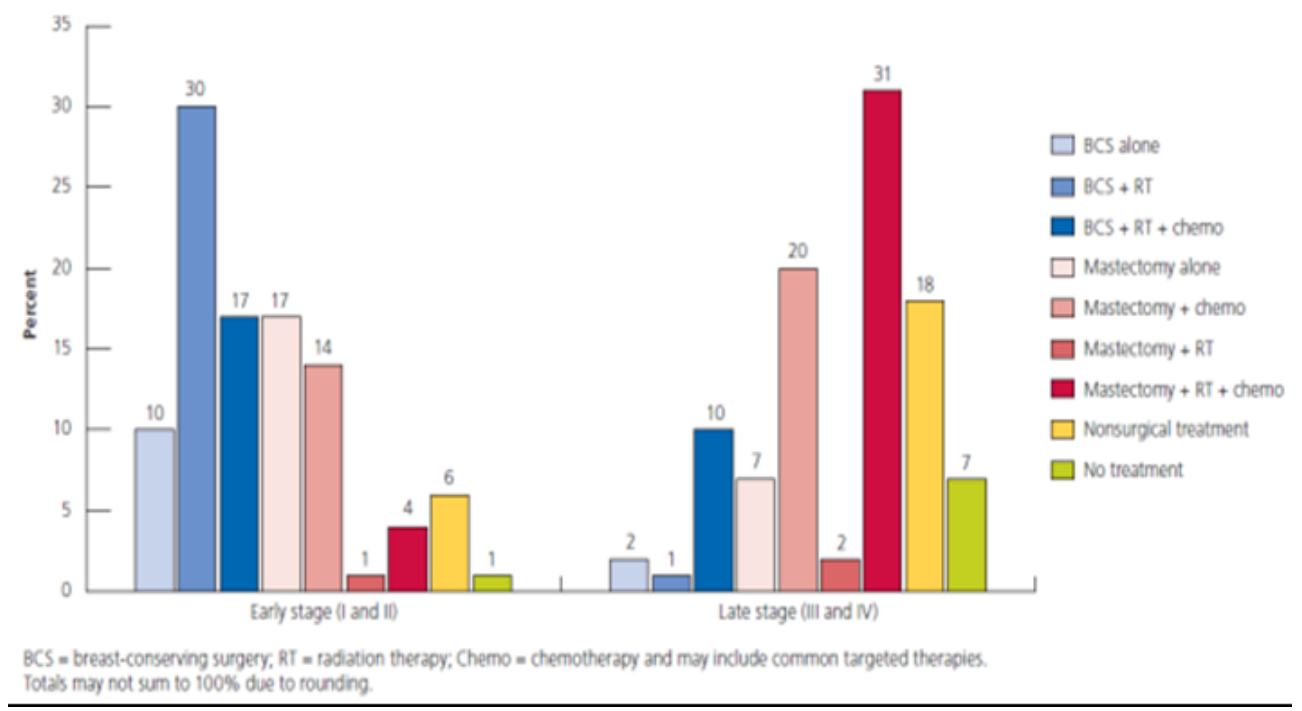

Figure 8: Distribution (\%) of selected cancers by race and stage at diagnosis, 2001-2007.

\section{Folate Targeting to Ovarian Cancer}

Ovarian cancer is a commonly diagnosed and particularly deadly gynecologic malignancy worldwide (Figure 9). It ranks among the top ten diagnosed cancers and top five deadliest cancers in most countries [64]. Several strategies have been employed to target ovarian cancer. A research report explains that $\alpha$-FR has a potential as a target for immunotherapeutic approaches in ovarian cancer. $\alpha$-FR is a tumorassociated antigen that induces detectable immune responses in $70 \%$ of patients with ovarian cancer [65]. EC145 is a drug that is specifically designed to enter cancer Race cells via the folate vitamin receptor (FR). Early clinical evidence in a small number of phase I patients suggest that EC145 has antitumor effect in women with advanced ovarian cancer [66]. The presence of endogenous immune reactivity raises the possibility that the immune response could be further enhanced by vaccines targeting the $\alpha$-FR [67]. Evaluation of the expression pattern and intracellular localization of $\alpha$-FR protein in human ovarian carcinoma compared with non-neoplastic ovarian tissue is analyzed in specimens of 104 human ovarian carcinomas and 30 non-neoplastic ovaries using immunohistochemistry (IHC). In $97 \%$ of the ovarian carcinomas, clear $\alpha$-FR protein expression is detected (14\% weak, $39 \%$ moderate, $44 \%$ strong). In the non-neoplastic ovaries, no (37\%) or only weak $(63 \%)$ expression is observed $(\mathrm{p}<0.0001)$. The tumor cells are characterized by a diffuse and homogeneous staining pattern. In tumor and non-tumor tissue, $\alpha$-FR protein is detected predominantly in the cellular cytoplasm. In $41 \%$ of the ovarian carcinomas, cytoplasmic expression is localized towards the outer borders of the invasive tumor cells and 30\% exhibit additional nuclear $\alpha$-FR protein expression. Compared with nonneoplastic ovaries, $\alpha$-FR protein is over expressed in human ovarian carcinoma tissue [17].

\section{Folate Targeting to Prostate Cancer}

Prostate specific membrane antigen (PSMA) is one of the most studied targets for prostate cancer treatment. PSMA, a class II transmembrane glycoprotein, is known to be over expressed by cancerous prostate tissue. PC-93 AD primary prostate cancer, 22Rv1 Derived from CWR22R are androgen-dependent prostate cancer xenograft lines (Figure 10). The Androgen Receptor (AR) is expressed in both androgen-dependent and -independent prostate cancers. Therefore, ARs might play an important role in the progression of androgen independence in prostate cancer. Most patients with 
Citation: Praveen Kumar G, Divya A (2015) Nanoemulsion Based Targeting in Cancer Therapeutics. Med chem 5: 272-284. doi: 10.4172/21610444.1000275

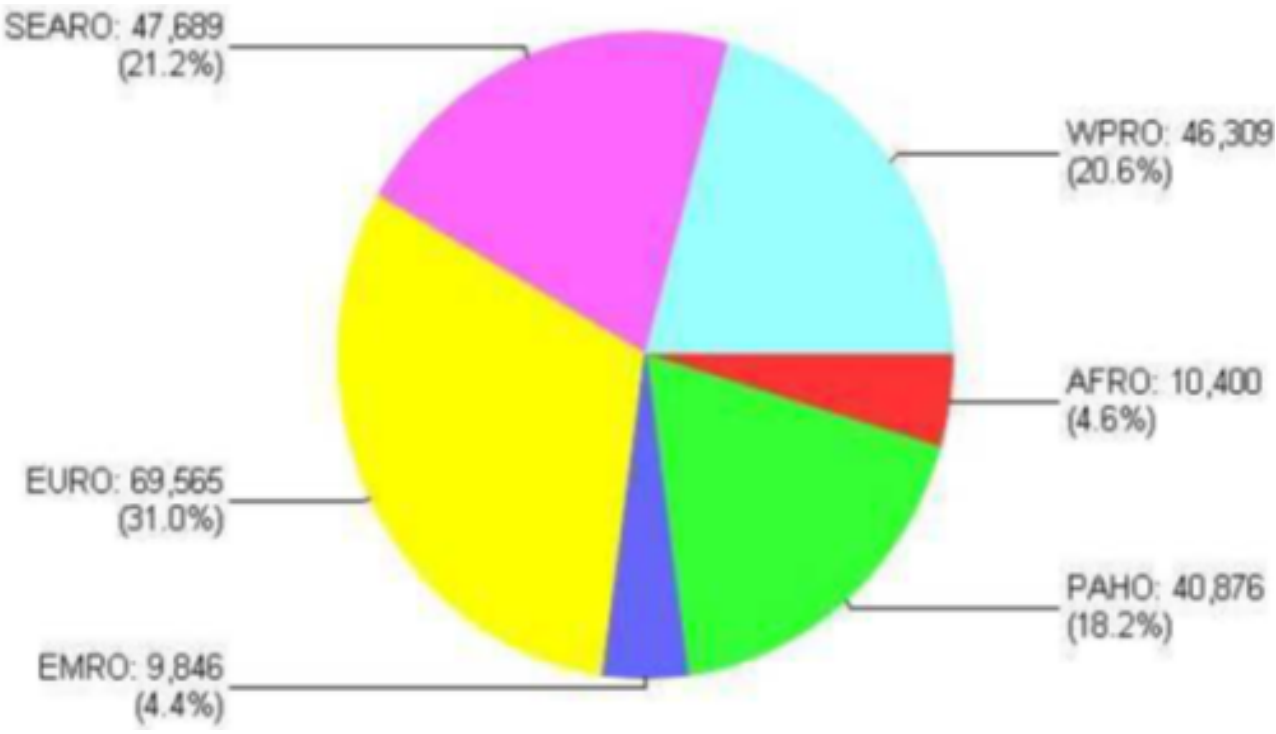

Figure 9: Percentage of ovarian cancer cases by World Health Organization (WHO).

SEARO: Southeast Asia Regional Office, EURO: European Regional Office; EMRO: Eastern Mediterranean Regional Office; WPRO: Western Pacific Regional Office; AFRO: Africa Regional Office; PAHO: Pan American Health Organization

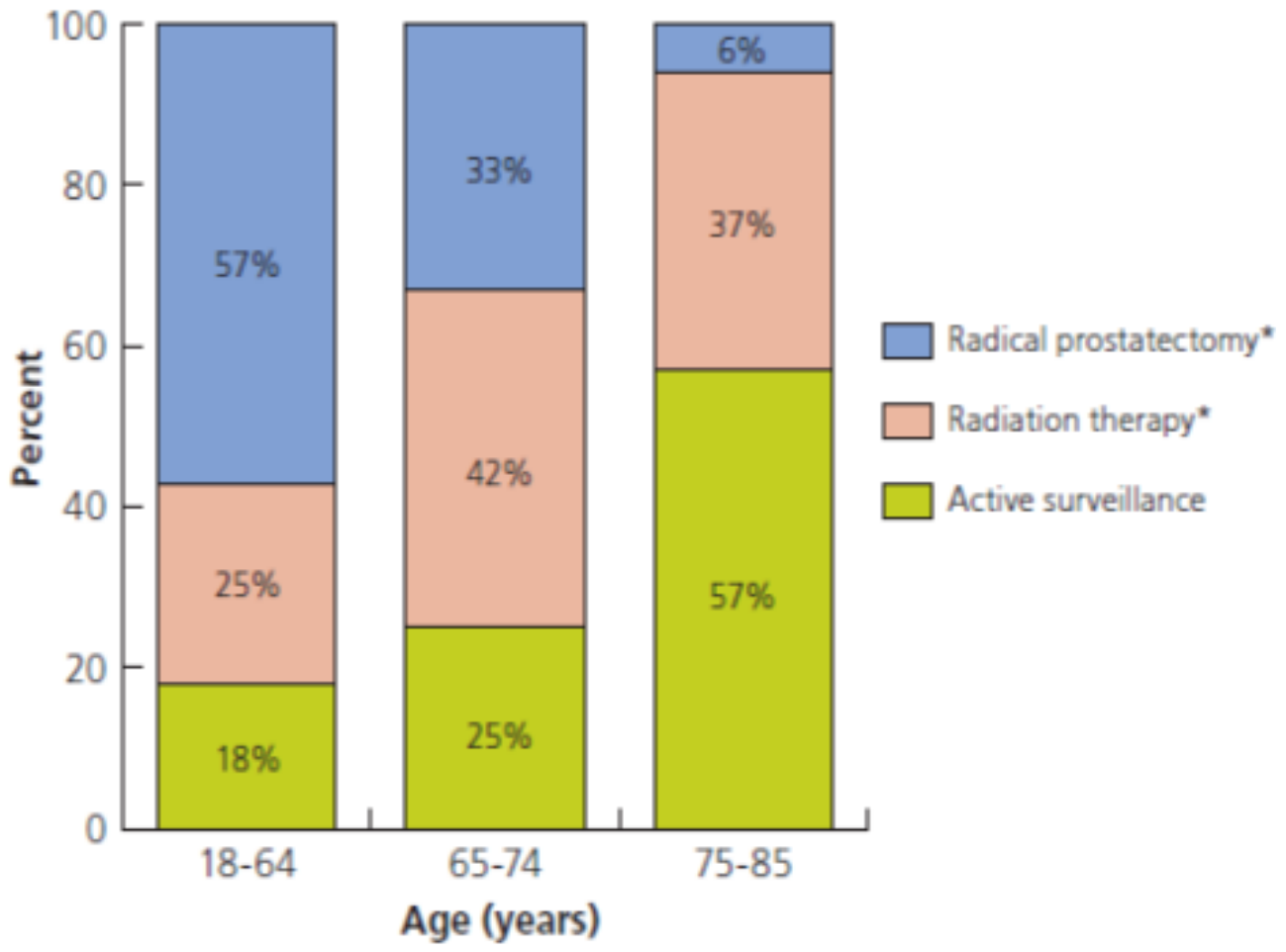

Figure 10: Prostate cancer primary treatment patterns by age, 2008.

metastatic prostate cancer initially respond to androgen ablation therapy. However, the cancer often recurs as an androgen-independent tumor that is difficult to treat. Thus, the progression from androgendependence to androgen independence is a critical step in the development of prostate cancer, yet the molecular mechanism is poorly understood. Loss of androgen sensitivity is generally considered to have four causes: selection of cancer clones; adaptation of cells to an environment without androgen; an alternative pathway of signal transduction; and involvement of ARs. Targeting prostate cancer tissue through PSMA involves folate ligands. PSMA is known to bind folate and can consequently be targeted by folate-modified drug carriers [68]. In a study [69], the cytotoxicity studies of curucumin solution and curcumin-loaded nanoemulsion with Soybean oil, hydrogenated 1- $\alpha$-phosphatidylcholine on B16F10 and leukemic cell lines show IC50 values ranging from 3.5 to 30.1 and 22.2 to $53.7 \mu \mathrm{M}$, respectively. These results demonstrate the successful incorporation of curcumin into 
lipid nanoemulsion with high cytotoxicity on prostate cancer cell lines (Figure 11). Therefore, from the studies it is evident that nanoemulsions are promising carriers to target to prostrate cancers .

\section{Nanoemulsions for Oligonucleotide Delivery to Tumor Cells}

Antisense oligonucleotides are tested widely in the past few years for the treatment of cancer [70-73]. However, poor stability mainly in biological fluids [74-76] and low intracellular penetration of these oligonucleotides (ODN) have limited their therapeutic use. Chemical modifications of the oligonucleotide phosphodiester backbones into phosphorothioate partially enhance the chemical stability to enzymatic degradation $[77,78]$ but do not improve the intracellular penetration. Furthermore, drug delivery systems based on liposomes still suffer from inherent limitations that restrict their potential due to stability issues. These limitations include instability and short shelf life, low drug-loading capacity, sensitivity to sterilization and expensive largescale manufacturing process .

It can be hypothesized that an association of ODN molecules with cationic oil nanodroplets will reduce significantly the polyanionic character of the ODN molecules (Figure 12). Novel formulations of

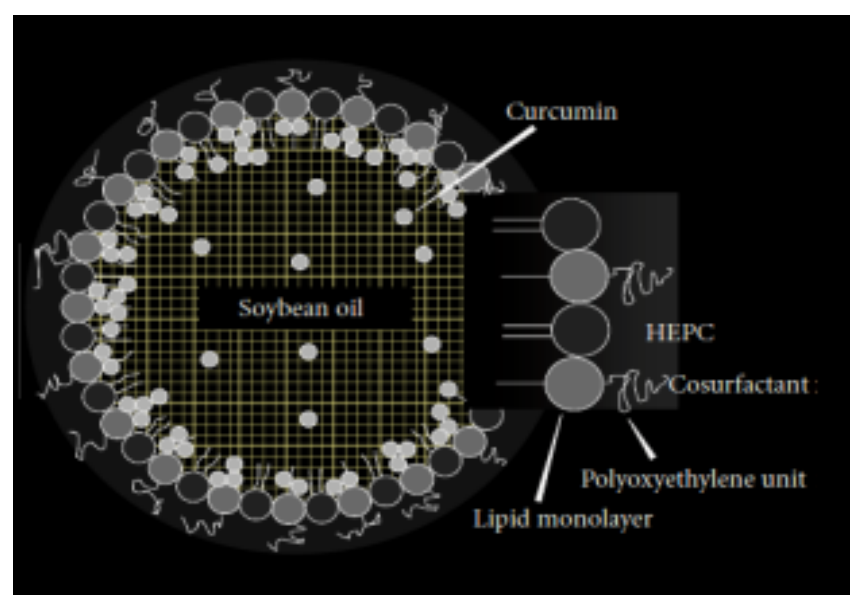

Figure 11: Curcumin-loaded lipid nanoemulsion.

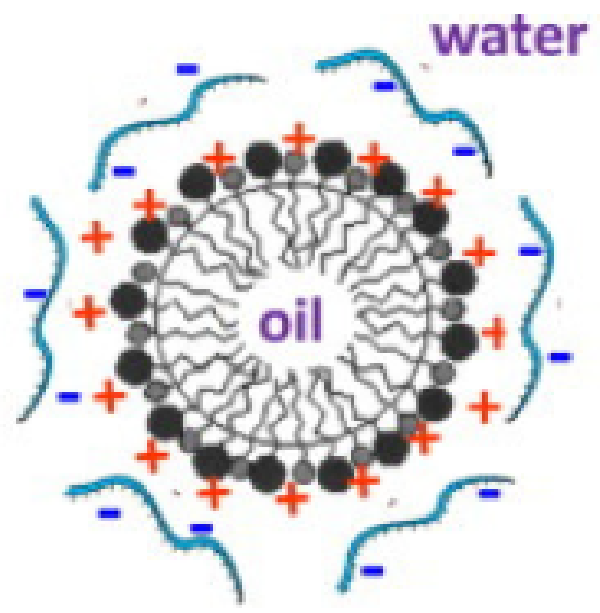

Figure 12: Nanoemulsion-oligonucleotide complex. cationic nanoemulsions based on three different lipids are developed to strengthen the attraction of the polyanionic oligonucleotide (ODN) macromolecules to the cationic moieties on the oil nanodroplets. DOTAP cationic lipid nanoemulsion is capable of retaining ODN despite the high dilution. Less than $10 \%$ of the ODN is exchanged in contrast to $40-50 \%$ with the other cationic nanoemulsions. The in-vitro release kinetic behavior of ODN exchange with physiological anions present in the STS appears to be complex and difficult to characterize using mathematical fitting model equations. Further pharmacokinetic studies are needed to verify our kinetic assumptions and confirm the invitro ODN release profile from DOTAP cationic nanoemulsions [79]. Recently, findings between structure of lipid-DNA complexes and their biological activity is gaining more interest [80-82]. One major drawback associated with in vivo lipid mediated gene delivery is relatively low transfection efficiency due to poor stability of the complex upon contact with serum $[83,84]$. Strong electrostatic interactions between positively charged lipid-DNA complexes and negatively charged proteins in the blood are responsible for the rapid aggregation of lipid-DNA complexes upon contact with serum. One way to overcome the problem of serum instability and to prolong their circulation time in the blood is to protect their surface by adding PE-PEG. When 9 or $10 \%$ (w/w) PE-PEG is added to the lipidic formulation, the plasma clearance as well as the liver uptake is considerably decreased. The addition of PE-PEG helps to prolong the circulation of the emulsion in the blood by shielding the positive surface charge and by providing a more hydrophilic surface [85]. However, these improvements are still not enough to obtain a DNA/emulsion delivery system that remains circulating for an extended period of time [86].

\section{Cytotoxicity of Nanoemulsions}

Current research is also focused on understanding and taking advantage of the features of tumor microenvironment such as $\mathrm{pH}$ and temperature changes. Systemic chemotherapy has been the most successful mode of cancer therapy for a long time. However, infusing therapeutic doses of cytotoxic drugs into the blood stream and achieving the desired concentration in the tumor without producing toxic effects in the healthy body tissues has been the biggest challenge in cancer chemotherapy. Similarly, gene delivery systems encountered the problem of insufficient uptake, cytotoxicity, and undesirable immunogenic side effects due to the lack of safe tissue or cell specific vectors. This problem is being largely addressed by the advent of numerous surface-modified nano-sized drug delivery systems that can escape the reticulo-endothelial system and reach the target tissue with the aid of various target-specific ligands upon systemic administration. Developing nanocarriers that employ various beneficial properties require the assembly of a number of chemical moieties on a single nanosystem. One of the challenges in the formulation of such nanosystems is cytotoxicity. Fang et al. [87] developed acoustically active nanoemulsions for camptothecin to test the efficiency of its cytotoxicity towards cancer cells. The nanoemulsions were prepared using liquid perfluorocarbons and coconut oil as oil cores of the inner phase. Camptothecin in nanoemulsions with a lower oil concentration exhibited cytotoxicity against melanomas and ovarian cancer cells. Confocal laser scanning microscopy confirmed nanoemulsion uptake into cells. Hemolytic studies to assess the interaction between erythrocytes and the nanoemulsions showed less hemolysis. Using a $1 \mathrm{MHz}$ ultrasound, an increased release of camptothecin from the system with lower oil concentration could be established, illustrating a drug-targeting effect. Also, local application of toxic doses of perfluorochemical nanoemulsions resulted in the necrosis of cancer cells. Thus, this is a classical example which is evident that campothecin in nanoemulsion is proved to be highly cytotoxic in vitro and in vivo. 
When multifunctional nanoemulsons formulated, these drug delivery systems could enable controlled and targeted release of drugs or therapeutic molecules at the site of action. Such multifaceted, versatile nanocarriers and drug delivery systems promise a substantial increase in the efficacy of therapeutic applications in pharmaceutical sciences and thus the adverse effects can further be reduced.

\section{Conclusion}

Nanoemulsions are being explored for cancer prevention, detection, and treatment. Methods are being proposed and tested that could make diagnosis and treatment of cancer non-invasive which can be targeted directly to tumors. The current drug technologies are modulated that can result in reduced toxicity, and in some cases, a 10-fold higher efficacy than when the drug is administered without targeting. The ability to target only cancer cells may prove to eliminate adverse effects of treatment such as damage to the immune system and the loss of quick replicating cells. The folate receptor appears to be a promising target for cancer imaging and treatment. Folate receptors are highly over expressed on the surface of many tumor types. This expression can be exploited to target therapeutic compounds directly to cancerous tissues using many avenues. While these studies prove to be promising, the use of folate directed cancer treatments in human subjects still needs further development and testing. The correct dosages and potential long-term effects of drug delivery for the treatment of cancer need to be still explored.

\section{Future Directions}

Novel drug delivery systems can enhance important characteristics of drugs such as bioavailability and drug solubility. Pharmacokinetic and pharmacodynamic properties of drug molecules can be improved by nanotechnology. In spite of all the possible advantages of nanosystems, they have some practical problems to overcome. Nanosystems have the potential to become one of the main human health care products in the future; therefore, the pharmaceutical nanotechnology area needs more studies so that we can completely understand their characteristics. Since the last couple of decades technology transfer has been playing an important role for the success of any new technology. In this regard, within a short span of time, nanoemulsion based delivery has moved from academic to industrial research. Recent advances in this field have led to creation of a wide variety of nanoemulsion formulations which are useful in delivering therapeutic agents via desired routes of administration, reducing the toxicity and increasing the therapeutic competence. As reviewed above, nanoemulsions are playing a very important role in cancer therapy. Till date, these nanoemulsions were investigated in terms of their ability to deliver anticancer drugs with respect to their physicochemical properties, drug loading and entrapment efficiency, and in vitro and in vivo efficiency and toxicity in animal models. But still more important issues, such as the role of these carriers in siRNA therapy, stability and other safety issues, need to be addressed before seeing them in the market. Nanotechnology is a fastexpanding area of science. This area of research is anticipated to lead to the development of novel, sophisticated, multifunctional applications which can recognize cancer cells, deliver drugs to target tissue, aid in reporting outcome of therapy, provide real-time assessment of therapeutic and surgical efficacy, and most importantly, monitor intracellular changes to help prevent precancerous cells from becoming malignant. On-going efforts by scientists, researchers, and medical personnel can sincerely ensure to "do big things using the very small".

\section{References}

1. Lovelyn C, Attama AA (2011) Current State of Nanoemulsions in Drug Delivery. J Biomater Nanobiotechnol 2: 626-639.
2. Constantinides PP, Lambert KJ, Tustian AK, Schneider B, Lalji S, et al. (2000) Formulation development and antitumor activity of a filter-sterilizable emulsion of paclitaxel. Pharmaceutical Research 17: 175-182.

3. Davis SS, Illum L, Washington C, Harper G (1992) Studies on the interaction of charge-reversed emulsions with the reticuloendothelial system. Int J Pharm 82: 99-105.

4. Ueda K, Ishida M, Inoue T, Fujimoto M, Kawahara Y, et al. (2000) Effect of injection volume on the pharmacokinetics of oil particles and incorporated menatetrenone after intravenous injection as O/W lipid emulsions in rats. J Drug Target 9: 353-360.

5. Hedeman H, Brondsted H, Mullertz A, Frokjaer S (1996) Fat emulsions based on structured lipids (,3-specific triglycerides): an investigation of the in vivo fate. Pharm Res 13: 725-728.

6. Takino T, Konishi K, Takakura Y, Hashida M (1994) Long circulating emulsion carrier systems for highly lipophilic drugs. Biol Pharm Bull 17: 121-125.

7. Takino T, Nakajima C, Takakura Y, Sezaki H, Hashida M (1993) Controlled biodistribution of highly lipophilic drugs with various parenteral formulations. $J$ Drug Target 1: 117-124

8. Arimoto I, Matsumoto C, Tanaka M, Okuhira K, Saito H, et al. (1998) Surface composition regulates clearance from plasma and triolein lipolysis of lipid emulsions. Lipids 33: 773-779.

9. Lin SY, Wu WH, Lui WY (1992) In vitro release, pharmacokinetic and tissue distribution studies of doxorubicin hydrochloride (Adriamycin $\mathrm{HCl}$ ) encapsulated in lipiodolized w/o emulsions and w/o/w multiple emulsions. Pharmazie 47: 439-443.

10. Ueda K, Yamazaki Y, Noto H, Teshima Y, Yamashita C, et al. (2003) Effect of oxyethylene moieties in hydrogenated castor oil on the pharmacokinetics of menatetrenone incorporated in $\mathrm{O} / \mathrm{W}$ lipid emulsions prepared with hydrogenated castor oil and soybean oil in rats. J Drug Target 11: 37-43.

11. Liu F, Liu D (1995) Long-circulating emulsions (oil-in-water) as carriers for lipophilic drugs. Pharm Res 12: 1060-1064.

12. Lee JH, Lee HB, Andrade JD (1995) Blood compatibility of polyethylene oxide surfaces. Prog Polym Sci 20: 1043-1079.

13. Levy MY, Benita S, Baszkin A (1991) Interactions of a non-ionic surfactant with mixed phospholipid-oleic acid monolayers. Studies under dynamic conditions. Colloids Surf 59: 225-241.

14. Harris JM, Martin NE, Modi M (2001) Pegylation: a novel process for modifying pharmacokinetics. Clin Pharmacokinet 40: 539-551.

15. Bhadra D, Bhadra S, Jain P, Jain NK (2002) Pegnology: a review of PEG-ylated systems. Pharmazie 57: 5-29.

16. Lundberg BB, Mortimer BC, Redgrave TG (1996) Submicron lipid emulsions containing amphipathic polyethylene glycol for use as drug-carriers with prolonged circulation time. Int J Pharm 134: 119-127.

17. Ferlay J, Shin HR, Bray F, Forman D, Mathers C, et al. (2010) Estimates of worldwide burden of cancer in 2008: GLOBOCAN 2008. Int J Cancer 127: 2893-2917.

18. Atlanta GA (2013) American Cancer Society. Cancer facts and figures. American Cancer Society.

19. Howlander N, Noone AM, Krapcho M, Neyman N, Aminou R, et al. (2012) Seer cancer statistics review, Bethesda, MD: National Institutes of Health.

20. O'connor S, Arriaga EE (1984) Mexico's demographic trends and employment prospects. Int Demogr 3: 3, 10-11.

21. Torchilin VP (2006) Nanoparticulates as Pharmaceutical Carriers. Imperial College Press, London, UK.

22. Lederer SE, Parascandola J (1998) Screening syphilis: Dr. Ehrlich's Magic Bullet meets the Public Health Service. J Hist Med Allied Sci 53: 345-370.

23. Makidon PE, Bielinska AU, Nigavekar SS, Janczak KW, Knowlton J, et al. (2008) Pre-clinical evaluation of a novel nanoemulsion-based hepatitis $B$ mucosal vaccine. PLoS One 3: e2954.

24. Bielinska AU, Janczak KW, Landers JJ, Markovitz DM, Montefiori DC, et al. (2008) Nasal immunization with a recombinant HIV gp120 and nanoemulsion adjuvant produces Th1 polarized responses and neutralizing antibodies to primary HIV type 1 isolates. AIDS Res Hum Retroviruses 24: 271-281.

25. Huang MH, Huang CY, Lin SC, Chen JH, Ku CC, et al. (2009) Enhancement 
of potent antibody and T-cell responses by a single-dose, novel nanoemulsionformulated pandemic influenza vaccine. Microbes Infect 11: 654-660.

26. Shi $R$, Hong L, Wu D, Ning $X$, Chen $Y$, et al. (2005) Enhanced immune response to gastric cancer specific antigen Peptide by coencapsulation with CpG oligodeoxynucleotides in nanoemulsion. Cancer Biol Ther 4: 218-224.

27. Hang QL, Ding J, Gong AC, Yu ZC, Qiao TD, et al. (2003) Screening of bioactive peptide that mimic the epitope of gastric cancer associated antigen. Xi Bao Yu Fen Zi Mian Yi Xue Za Zhi 19: 308-310.

28. Xu L, Jin BQ, Fan DM (2003) Selection and identification of mimic epitopes for gastric cancer-associated antigen MG7 Ag. Mol Cancer Ther 2: 301-306.

29. Ge W, Sui YF, Wu DC, Sun YJ, Chen GS, et al. (2006) MAGE-1/Heat shock protein 70/MAGE-3 fusion protein vaccine in nanoemulsion enhances cellular and humoral immune responses to MAGE-1 or MAGE-3 in vivo. Cancer Immunol Immunother 55: 841-849.

30. Ge W, Sun YJ, Li Y, Zhang SH, Zhang XM, et al. (2008) Anti-tumor immune responses of nanoemulsion-encapsulated MHS vaccine. Xi Bao Yu Fen Zi Mian Yi Xue Za Zhi 24: 457-460.

31. Ge W, Hu PZ, Huang Y, Wang XM, Zhang XM, et al. (2009) The antitumor immune responses induced by nanoemulsionencapsulated MAGE1-HSP70/ SEA complex protein vaccine following different administration routes. Oncol Rep 22: 915-920.

32. Ge W, Li Y, Li ZS, Zhang SH, Sun YJ, et al. (2009) The antitumor immune responses induced by nanoemulsionencapsulated MAGE1-HSP70/SEA complex protein vaccine following peroral administration route. Cancer Immunol Immunother 58: 201-208.

33. Jabr-Milane LS, van Vlerken LE, Yadav S, Amiji MM (2008) Multi-functiona nanocarriers to overcome tumor drug resistance. Cancer Treat Rev 34: 592-602.

34. Peer D, Karp JM, Hong S, Farokhzad OC, Margalit R, et al. (2007) Nanocarriers as an emerging platform for cancer therapy. Nat Nanotechnol 2: 751-760.

35. Ganta S, Amiji M (2009) Coadministration of Paclitaxel and Curcumin in Nanoemulsion Formulations to Overcome Multidrug Resistance in Tumor Cells Mol. Pharmaceutics 6: 928-939.

36. Harris M (2004) Monoclonal antibodies as therapeutic agents for cancer Lancet Oncol 5: 292-302.

37. Adams GP, Weiner LM (2005) Monoclonal antibody therapy of cancer. Nat Biotechnol 23: 1147-1157.

38. Lane D (2006) Designer combination therapy for cancer. Nat Biotechnol 24 163-164.

39. Spicer J, Harries M, Ellis P (2005) Adjuvant trastuzumab for HER2-positive breast cancer. Lancet 366: 634

40. Schrama D, Reisfeld RA, Becker JC (2006) Antibody targeted drugs as cancer therapeutics. Nat Rev Drug Discov 5: 147-159.

41. Raben D, Helfrich B, Chan DC, Ciardiello F, Zhao L, et al. (2005) The effects of cetuximab alone and in combination with radiation and/or chemotherapy in lung cancer. Clin Cancer Res 11: 795-805.

42. Goldstein D, Sader O, Benita S (2007) Influence of oil droplet surface charge on the performance of antibody--emulsion conjugates. Biomed Pharmacother 61: 97-103.

43. Lundberg BB, Griffiths G, Hansen HJ (1999) Conjugation of an anti-B-cell lymphoma monoclonal antibody, LL2, to long-circulating drug-carrier lipid emulsions. J Pharm Pharmacol 51: 1099-1105.

44. Lundberg BB, Griffiths G, Hansen HJ (2004) Cellular association and cytotoxicity of anti-CD74-targeted lipid drug-carriers in B lymphoma cells. J Control Release 94: 155-161.

45. Goldstein D, Nassar T, Lambert G, Kadouche J, Benita S (2005) The design and evaluation of a novel targeted drug delivery system using cationic emulsionantibody conjugates. J Control Release 108: 418-432.

46. Song YK, Liu D, Maruyama KZ, Takizawa T (1996) Antibody mediated lung targeting of long-circulating emulsions. PDA J Pharm Sci Technol 50: 372-377.

47. Reubi JC (2003) Peptide receptors as molecular targets for cancer diagnosis and therapy. Endocr Rev 24: 389-427.

48. Villalba M, Coudronniere N, Deckert M, Teixeiro E, Mas P, et al. (2000) A nove functional interaction between Vav and PKCtheta is required for TCR-induced T cell activation. Immunity 12: 151-160.
49. Deddens LH (2003) Developed nanoemulsions in which cyclic RGD peptides were conjugated via a sulfhydryl-maleimide coupling method and demonstrated that application of avß3-targeted RGD-NE for molecular MRI of tumor angiogenesis revealed a high degree of specificity by means of fluorescence microscopy an immunohistochemistry. Endocrine Reviews 24: 389-427.

50. Nikanjam M, Gibbs AR, Hunt CA, Budinger TF, Forte TM (2007) Synthetic nanoLDL with paclitaxel oleate as a targeted drug delivery vehicle for glioblastoma multiforme. J Control Release 124: 163-171.

51. Song YC, Cheng HY, Leng CH, Chiang SK, Lin CW, et al. (2013) A nove emulsion-type adjuvant containing $\mathrm{CpG}$ oligodeoxynucleotides enhances CD8+ T-cell-mediated anti-tumor immunity. Journal of Controlled Release 173 158-165.

52. Jaracz S, Chen J, Kuznetsova LV, Ojima I (2005) Recent advances in tumortargeting anticancer drug conjugates. Bioorg Med Chem 13: 5043-5054.

53. Luhrs CA, Slomiany BL (1989) A human membrane-associated folate binding protein is anchored by a glycosyl-phosphatidylinositol tail. J Biol Chem 264 21446-21449.

54. Kamen BA, Wang MT, Streckfuss AJ, Peryea X, Anderson RG (1988) Delivery of folates to the cytoplasm of MA104 cells is mediated by a surface membrane receptor that recycles. J Biol Chem 263: 13602-13609.

55. Low PS, Antony AC (2004) Folate receptor-targeted drugs for cancer and inflammatory diseases. Adv Drug Deliv Rev 56: 1055-1058.

56. Elnakat H, Ratnam M (2004) Distribution, functionality and gene regulation of folate receptor isoforms: implications in targeted therapy. Adv Drug Deliv Rev 56: 1067-1084

57. Zhao X, Li H, Lee RJ (2008) Targeted drug delivery via folate receptors. Expert Opin Drug Deliv 5: 309-319.

58. Bae PK, Jung J, Lim SJ, Kim D, Kim SK, et al. (2013) Bimodal perfluorocarbon nanoemulsions for nasopharyngeal carcinoma targeting. Mol Imaging Biol 15 401-410.

59. Antony AC, Kane MA, Portillo RM, Elwood PC, Kolhouse JF (1985) Studies of the role of a particulate folate-binding protein in the uptake of 5-methyltetrahydrofolate by cultured human KB cells. J Biol Chem 260: 1491114917.

60. Antony AC (1996) Folate receptors. Annu Rev Nutr 16: 501-521.

61. Shannessy JO, Somers EB, Maltzman J, Smale R, Fu YS (2012) Folate receptor alpha (FRA) expression in breast cancer: identification of a new molecular subtype and association with triple negative disease 1: 1-9.

62. Gopani H (2011) Combination chemo and hyperoxia therapy in breast cance cells using nanoemulsion delivery systems. Bouvé College of Health Sciences. Pharmaceutical Science Master's Theses.

63. Mendes S, Graziani SR, Vitorio TS, Padoveze AF, Hegg R, et al. (2009) Uptake by breast carcinoma of a lipidic nanoemulsion after intralesional injection into the patients: a new strategy for neoadjuvant chemotherapy. Gynecol Onco 112: 400-404.

64. Knutson KL, Krco CJ, Erskine CL, Goodman K, Kelemen LE, et al. (2006) T-cell immunity to the folate receptor alpha is prevalent in women with breast or ovarian cancer. J Clin Oncol 24: 4254-4261.

65. Campos SM, Ghosh S (2010) A current review of targeted therapeutics for ovarian cancer. J Oncol 2010: 149362.

66. Armstrong DK, Bicher A, Coleman RL (2008) Exploratory phase II efficacy study of MORAb-003, a monoclonal antibody against folate receptor alpha, in platinumsensitive ovarian cancer in first relapse, Journal of Clinical Oncology 26: 5500 .

67. Markert S, Lassmann S, Gabriel B (2008) Alpha folate receptor expression in epithelial ovarian carcinoma and nonneoplastic ovarian tissue. Anticancer Research 28: 3567-3572.

68. Byrne JD, Betancourt T, Brannon-Peppas L (2008) Active targeting schemes for nanoparticle systems in cancer therapeutics. Adv Drug Deliv Rev 60: 16151626

69. Anuchapreeda S, Fukumori Y, Okonogi S, Ichikawa H (2012) Preparation of Lipid Nanoemulsions Incorporating Curcumin for Cancer Therapy. Journal of Nanotechnology 1-11.

70. Sahu NK, Shilakari G, Nayak A, Kohli DV (2007) Antisense technology: a selective tool for gene expression regulation and gene targeting. Curr Pharm Biotechnol 8: 291-304. 
Citation: Praveen Kumar G, Divya A (2015) Nanoemulsion Based Targeting in Cancer Therapeutics. Med chem 5: 272-284. doi: 10.4172/21610444.1000275

71. Isomura I, Morita A (2006) Regulation of NF-kappaB signaling by decoy oligodeoxynucleotides. Microbiol Immunol 50: 559-563.

72. Lebedeva IV, Stein CA (2000) Antisense oligonucleotides in cancer: recent advances. BioDrugs 13: 195-216.

73. James W (2007) Aptamers in the virologists' toolkit. J Gen Virol 88: 351-364.

74. Teixeira H, Dubernet C, Puisieux F, Benita S, Couvreur P (1999) Submicron cationic emulsions as a new delivery system for oligonucleotides. Pharm Res 16: $30-36$.

75. Lysik MA, Wu-Pong S (2003) Innovations in oligonucleotide drug delivery. J Pharm Sci 92: 1559-1573.

76. Toub N, Malvy C, Fattal E, Couvreur P (2006) Innovative nanotechnologies for the delivery of oligonucleotides and siRNA. Biomed Pharmacother 60: 607-620.

77. Bochot A, Couvreur P, Fattal E (2000) Intravitreal administration of antisense oligonucleotides: potential of liposomal delivery. Prog Retin Eye Res 19: 131-147.

78. Fattal E, Couvreur P, Dubernet C (2004) "Smart" delivery of antisense oligonucleotides by anionic $\mathrm{pH}$-sensitive liposomes. Adv Drug Deliv Rev 56: 931-946.

79. Hagigit T, Nassar T, Behar-Cohen F, Lambert G, Benita S (2008) The influence of cationic lipid type on in-vitro release kinetic profiles of antisense oligonucleotide from cationic nanoemulsions. Eur J Pharm Biopharm 70: 248-259.
80. Lin AJ, Slack NL, Ahmad A, Koltover I, George CX, et al. (2000) Structure and structure-function studies of lipid/plasmid DNA complexes. J Drug Target 8: 13-27.

81. Templeton NS, Lasic DD, Frederik PM, Strey HH, Roberts DD, et al. (1997) Improved DNA: liposome complexes for increased systemic delivery and gene expression. Nat Biotechnol 15: 647-652.

82. Tam P, Monck M, Lee D, Ludkovski O, Leng EC, et al. (2000) Stabilized plasmid-lipid particles for systemic gene therapy. Gene Ther 7: 1867-1874

83. Hong K, Zheng W, Baker A, Papahadjopoulos D (1997) Stabilization of cationic liposome-plasmid DNA complexes by polyamines and poly(ethylene glycol)phospholipid conjugates for efficient in vivo gene delivery. FEBS Lett 400: 233-237.

84. Li S, Tseng WC, Stolz DB, Wu SP, Watkins SC, et al. (1999) Dynamic changes in the characteristics of cationic lipidic vectors after exposure to mouse serum: implications for intravenous lipofection. Gene Ther 6: 585-594.

85. Lundberg BB, Mortimer BC, and Redgrave TG (1996) Submicron lipid emulsions containing amphipathic polyethylene glycol for use as drug-carriers with prolonged circulation time. Int J Pharm 134: 119-127.

86. Chesnoy S, Durand D, Doucet J, Stolz DB, Huang L (2001) Improved DNA Emulsion Complex Stabilized by poly(ethylene glycol) Conjugated Phospholipid. Pharmaceutical Research18: 1480-1484.

87. Fang JY, Hung CF, Hua SC, Hwang TL (2009)Acoustically active perfluorocarbon nanoemulsions as drug delivery carriers for camptothecin: drug release and cytotoxicity against cancer cells. Ultrasonics 49: 39-46. 